\title{
The Role of Nanodispersed Catalysts in Microwave Application during the Development of Unconventional Hydrocarbon Reserves: A Review of Potential Applications
}

\author{
Alexey V. Vakhin ${ }^{1, *}$, Mohammed Amine Khelkhal ${ }^{1}\left({ }^{\circledR}\right.$, Arash Tajik ${ }^{1}$, Marat R. Gafurov ${ }^{1}{ }^{\circledR}$, Oleg G. Morozov ${ }^{2}(\mathbb{D}$, \\ Aydar R. Nasybullin ${ }^{2}$, Sergey A. Karandashov ${ }^{2}$, Andrey A. Ponomarev ${ }^{3}$, Tatiana O. Krapivnitskaia ${ }^{4}$, \\ Mikhail Yu. Glyavin ${ }^{4}$ (D) Olga V. Slavkina ${ }^{5}$ and Konstantin A. Shchekoldin ${ }^{5}$ \\ 1 Institute of Geology and Petroleum Technologies, Kazan Federal University, 18 Kremlyovskaya St., \\ 420008 Kazan, Russia; aminekhelkhal@gmail.com (M.A.K.); atajik1989@gmail.com (A.T.); \\ mgafurov@gmail.com (M.R.G.) \\ 2 Institute of Radio Electronics and Telecommunications, Kazan National Research Technical University \\ Named after A.N. Tupolev-KAI, 10 K. Marx St., 420111 Kazan, Russia; microoil@mail.ru (O.G.M.); \\ aydar.nasybullin@mail.ru (A.R.N.); seregak2005@yandex.ru (S.A.K.) \\ 3 Institute of Geology and Oil and Gas Production, Tyumen Industrial University, 38 Volodarsky St., \\ 625000 Tyumen, Russia; ponomarev94@mail.ru \\ check for \\ updates \\ Citation: Vakhin, A.V.; Khelkhal, \\ M.A.; Tajik, A.; Gafurov, M.R.; \\ Morozov, O.G.; Nasybullin, A.R.; \\ 4 Institute of Applied Physics, Russian Academy of Sciences, 46 Ulyanova St., 603950 Nizhniy Novgorod, \\ Russia; kto465@yandex.ru (T.O.K.); glyavin@appl.sci-nnov.ru (M.Y.G.) \\ 5 OJSC RITEK, 85 Lesogorskya St., 400048 Volgograd, Russia; olga.slavkina@lukoil.com (O.V.S.); \\ Konstantin.schekoldin@lukoil.com (K.A.S.) \\ * Correspondence: vahin-a_v@mail.ru
}

Karandashov, S.A.; Ponomarev, A.A.; Krapivnitskaia, T.O.; Glyavin,

M.Y.; et al. The Role of

Nanodispersed Catalysts in

Microwave Application during the

Development of Unconventional

Hydrocarbon Reserves: A Review of

Potential Applications. Processes 2021,

9, 420. https://doi.org/10.3390/

pr9030420

Academic Editor: Farid B. Cortés

Received: 10 January 2021

Accepted: 19 February 2021

Published: 26 February 2021

Publisher's Note: MDPI stays neutral with regard to jurisdictional claims in published maps and institutional affiliations.

Copyright: () 2021 by the authors Licensee MDPI, Basel, Switzerland. This article is an open access article distributed under the terms and conditions of the Creative Commons Attribution (CC BY) license (https:/ / creativecommons.org/licenses/by/ $4.0 /)$

\begin{abstract}
Electromagnetic impact on oil reservoir manifests itself in various physical and chemical phenomena and attracts a significant scientific and technological interest. Microwave (MW) radiation heating can be more efficient for the oil recovery than heat transfer by convection or by thermal conduction. MW influence can also lead to significant changes in the physicochemical and rheological properties of oil caused by chemical processes of transformation of the oil high-molecular components such as resins and asphaltenes. The efficiency of transition-metal catalysts applied for the in-situ conversion of hydrocarbons directly in the reservoir might be significantly increased by exposing the oil formation to MW radiation. Actually, transition metals nanoparticles and their oxides are considered as active absorbers of MW radiation and; therefore, they can be used to intensify MW impact on the reservoir. Catalyst particles dispersed in the formation provide enhanced MW sweep. Taken together, the functioning of the catalysts and the effect of microwave radiation provide deep conversion of resins and asphaltenes, a decrease in the viscosity of the produced oil and an increase in oil recovery factor, along with a decrease in water cut of the well production. The present review analyzes the latest works on the combined application of microwave exposure and dispersed catalysts. In addition, this review discusses the prospects and perspectives of practical application of electromagnetic heating to enhance heavy oil recovery in the presence of nanoparticles.
\end{abstract}

Keywords: heavy oil; asphaltenes; microwave; electromagnetic heating; nano-metal particles; transitional metals; catalysis; in-situ upgrading

\section{Introduction}

Nowadays, the amount of unconventional oil reserves is greater than that of conventional oils. From another side, the population in the world is increasing significantly which leads to high demand of energy and hence more resources, such as heavy and extra-heavy oil. However, these types of hydrocarbons (heavy and extra-heavy oil) require modern and well-developed methods of extraction known as enhance oil recovery methods. Literally, there is a wide range of enhanced oil recovery (EOR) methods and they may be classified 
as thermal, chemical or even physical based on the followed technology during their application. Among the widely used methods for heavy and extra-heavy oil extraction, thermal methods basing on heat injection into the reservoir are generating a considerable interest [1-3]. Enhanced oil recovery is achieved by reducing the viscosity and partial chemical conversion of heavy hydrocarbons molecules [4-8]. A promising way to optimize thermal enhanced oil recovery is the injection of various catalysts into the reservoir, in order to stimulate cracking reactions, hydrolysis and destructive hydrogenation of resins and asphaltenes. Recently, some works have been performed by using nano-sized metalcontaining particles injected into the reservoir. It has been found that the conversion degree increases as a result of a more uniform coverage of the sample by heat exposure [9-13]. What is more, it has been found that transition metals nanoparticles have the ability to stimulate the process of resins and asphaltenes in-situ conversion in the reservoir [14-19].

In fact, the combination of thermal techniques and microwave (MW) radiation is generating more interest in terms of treating and exploiting formations with low thermal conductivity and low permeability containing heavy oil or bitumen [20]. Microwave treatment can be effective when it comes to oil shale exploitation [21], carbonate reservoirs development [22] and the exploitation of biomass waste [23]. In their work [24], Franus et al. have studied the effect of microwave heating time on the properties of lightweight aggregates. Authors have reported the strong effect generated by microwave heating on the compressive strength in addition to chemical content of the studied objects. Other works have studied, as well, the effect of different catalysts in the presence different substances, such as wastewater [25,26] and dihydroxybenzenes [27], in the presence of different frequency light, and have showed the efficiency of coupling light with catalysts in order to achieve a high yield of the desired product and enhance the rate of decolorization reactions.

Many applications of microwave heating have been reported in the literature, such as in chain polyglycerol production [28], residue char derived and wood sawdust mixed with activated carbon pyrolysis $[29,30]$, in addition to their utilization with different catalysts of different characteristics [31,32]. All the aforementioned works point toward the important practical significance of using microwave heating in industrial processes and express the potential effect that may generate in the field of enhancing heavy oil and shale oil recovery.

The next decade is likely to witness a particular interest in terms of developing in-situ microwave effect on unconventional oil reservoirs in the presence of catalyst particles. It is well known that microwave radiation can be converted into thermal energy at the surface of catalyst particles, which; therefore, leads to create the required conditions for deep conversion of asphaltenes contained in heavy oil or kerogen obtained from shale rocks. Our knowledge of microwave heating effect on enhanced heavy oil recovery methods in the presence of dispersed nanoparticles is largely based on very limited data. The aim of the present review was; therefore, to summarize the current level of research in the field of application of microwave heating in the presence of different catalysts together with nanoparticles, in order to highlight some advancement in enhancing unconventional oil in-situ recovery and to outline possible applications and implications of microwave heating technologies.

\section{Some Aspects about Microwave Heating Mechanisms during Enhanced Heavy Oil Thermal Recovery}

It is widely believed that microwave electromagnetic (EM) radiation ranges between $300 \mathrm{MHz}$ and $300 \mathrm{GHz}$. In other words, between the radio and infrared frequencies, with this corresponding to wavelengths in a vacuum of about $1 \mathrm{~m}$ to $1 \mathrm{~mm}$. Nowadays, frequencies ranging between $915 \mathrm{MHz}, 2.45 \mathrm{GHz}$ and $5.85 \mathrm{GHz}$ are the most commonly available frequencies used in chemical processes, scientific and medical bands to eliminate any interference with broadcast and communication bands [33].

Microwave catalytic methods and technologies are occurring, in most cases, in liquidphase or at the interfaces with a solid phase. In their work [34], authors have provided a physical explanation of the effects of generation and exposure to radio waves and microwaves in physicochemical processes. The effects of spin catalysis may differ in each 
individual reaction. However, the general tendency of an increase in the rate constant and a decrease in the activation energy is observed in many of the studied reactions, including hydrogenation, oxidation, isomerization and other reactions [35], which can not only be accelerated by a radio-frequency field, but may themselves present a source of radio frequency field. Microwave pumping of radical pairs induces electron-spin transitions, and when the frequency coincides with the frequencies of magnetic resonance transitions (electron paramagnetic resonance) in radicals, spin conversion accelerates and the yield of products increases [36].

In a recent work [37], the authors have found out that microwave heating of a carbon materials leads to the formation of two different types of plasma: ball lightening and an arc discharge plasma. It has been reported that hot spots affect the catalytic process and the stirring rate of the heterogeneous mixture (Figure 1). In addition, this study has shown that continuous and pulsed microwaves have a weak effect on the yield, unlike the mass transfer, presence and absence of standing wave which have a strong effect on the yield [38].
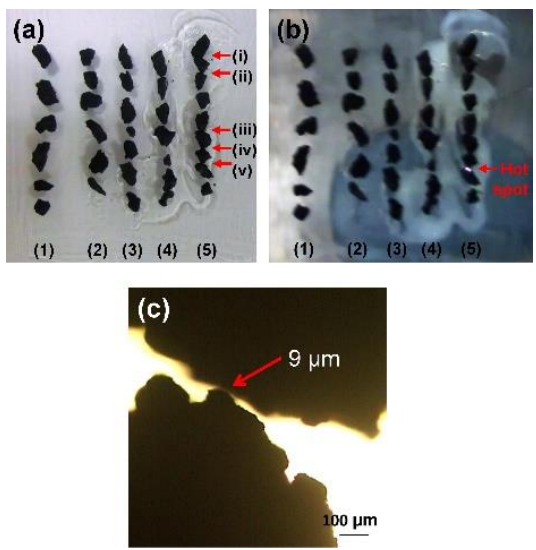
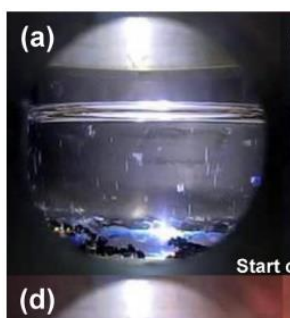

(d)

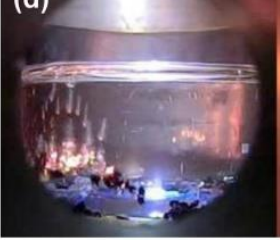

(b)

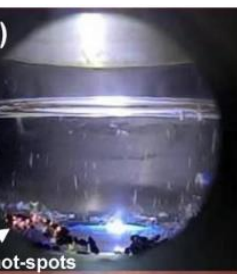

(e)

(e)

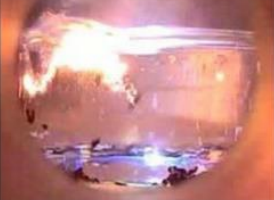

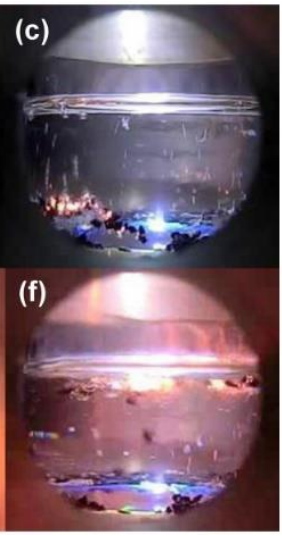
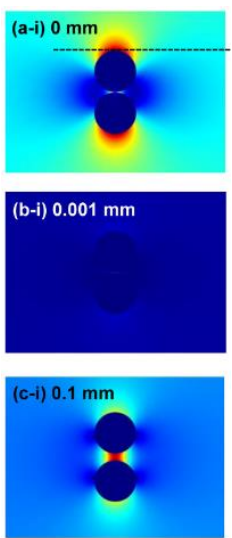

Figure 1. hot spots generated in activated carbon particles fixed at various intervals on a glass plate: (a) the initial sample; (b) formation of hot spots between the activated carbon particles under microwave irradiation; (c) observed distance between the particles in column (4) with an optical microscope (left). High-speed camera photograph of the electrical arc discharge occurring on the activated carbon in toluene solvent under the microwaves' E-field irradiation (center) where (a) shows bubbles on the activated carbon surface after 3s, (b) shows an orange-colored light from the aggregated activated carbon particles after $16 \mathrm{~s}$ at the lower left position, (c) shows greater number of bubbles formed around the emitted light, (d) shows the intense luminescence on the activated carbon surface, (e) shows the light from the hot spots reaching maximum intensity, (f) shows the redispersion of aggregated activated carbon particles and disappearance of luminescence from the activated carbon surface. Distribution of the microwaves' E-fields $(2.45 \mathrm{GHz})$ around two activated carbon particles in toluene solvent simulated with the COMSOL Multiphysics software version 4.3a. Colored images (a-i), (b-i) and (c-i) display the E-field intensity in two activated carbon particles in toluene together with the magnitude of the gap between the particles, whereas a-ii, b-ii and c-ii graphics show the magnitude of the E field ( $\left.\mathrm{V} \mathrm{m}^{-1}\right)$ within this gap (right). Reproduced with permission from [38], Copyright Elsevier, 2013.

Moreover, it has been established in [38,39] that mass transfer does not affect the yields, which remain constant at a certain stirring rate $(1500 \mathrm{rpm})$. However, below this value the mass transfer and hot spot, in addition to microwave input power levels, may play a crucial role in the extent of the obtained products.

However, a detailed explanation of microwave heating effects could not be achieved only by "hot spots" hypothesis. In their work [40], authors have showed that microwave heating is able to decrease the reaction energy of activation significantly in the presence of catalytic agent than the effect, which could be generated by the same equivalent thermal energy in the absence of catalysts.

Hydroxyl generation: Researchers have studied the electric current generated by semiconductor catalysts by microwave irradiation. MW irradiates on the semiconductor 
materials, leading to generate electric current and electron-holes pairs, on the semiconductor materials and on the MW catalyst [41]. This study established that semiconductor catalysts generate electric current and electron-holes pairs in the presence of microwave radiation. In addition, it has been found that the microwave radiation transforms the water existing on the surface of catalysts into hydroxyl free radicals $(\cdot \mathrm{OH})$ able to stimulate the reaction medium.

An electric field oscillating at a high frequency promotes the breaking of chemical bonds. For example, hydrogen sulfide could be formed from petroleum pitch with a high sulfur content in the presence of a catalyst, thus could be utilized. Moreover, it is widely believed that microwave exposure can be equivalent to thermal heating in hydrodesulfurization reactions of thiophene [42].

\section{Microwave Heating Impact on Hydrocarbons Structure}

It has been shown that asphaltenes possess the greatest ability to absorb the microwave field. In the molecular scale, oil asphaltenes present induced dipoles that agglomerate into nano-colloids with different aggregation degrees. Actually, combining oil asphaltenes with microwave power may overcome charge transfer and charge balance interactions with micelle agglomerates [32,43]. Previous works [44] have studied the mixture effect on the dilatation rheology of asphaltenes-laden interfaces and have accentuated on the importance of reinterpretation of asphaltenes adsorption properties mechanism investigation for a well-understanding of emulsion breaking during heavy oil recovery methods. We believe that, in addition to studying asphaltenes adsorption mechanism, it would be of great interest to study as well the mechanism of asphaltenes conversion in the presence of microwave radiation.

Microwave radiation is well absorbed by a number of substances, and heating is more efficient than heat transfer by convection or thermal conduction. The transformation of electrical energy into heat occurs due to the excitation of the microwave field of rotation or vibrations of molecules throughout the volume. Microwave radiation makes it possible to achieve almost instantaneous heating of a substance to a given temperature. The energy of the microwave field is eight orders of magnitude lower than the thermal energy, however, in some cases, the use of microwave radiation speeds up the reactions by hundreds of times. This is an environmentally friendly method of exposure. Under certain conditions, deep conversion of various high molecular weight hydrocarbons could be achieved [45].

The electromagnetic effect of the ultrahigh-frequency range on the reservoir system leads to the emergence of various physical and chemical phenomena [46]. The transformation of electrical energy into heat occurs because of microwave field excitation of molecules rotation and vibration throughout the volume. In fact, microwave radiation allows achieving almost instantaneous heating of any substance to a given temperature. Moreover, heat accumulation and transfer throughout any medium, whether inert or with reactants, in the presence of catalysts is significant for high-temperature endothermic processes. It is well known that microwave radiation is used in chemical industries to improve energy and mass transfer during rectification, dehydrogenation and thermal decomposition of carbonates [47]. Microwave exposure instead of using various coolants allows simplifying process flow diagrams by eliminating processes and devices that provide coolant preparation, and to reduce harmful emissions into the atmosphere.

The use of microwave radiation is effective for heavy oil feedstock and various oil pollution breaking down. It is an environmentally friendly recycling method. In fact, deep conversion of various high molecular weight hydrocarbons could be achieved under certain conditions.

Oil wells and pipelines are presenting transmission lines for electromagnetic waves, which may be lost partially or completely because of its interaction with the oil filling the pipe or in the annular space. With the correct selection of the transmission line parameters and the selection of the method of exciting electromagnetic energy in accordance with the 
dielectric properties of the oil, the content of the pipeline can be effectively heated to the wax melting point and thus prevent the formation of sediment [48].

It is common knowledge that the decomposition of tar under the influence of microwave energy leads to the formation of hydrogen and carbon monoxide at more than $93 \%$ of total content, with a predominance of hydrogen. During microwave treatment, the predominance of hydrogen is explained mainly by the activation and the destruction of $\mathrm{C}-\mathrm{H}$ bond. However, the convective heating target mainly the $\mathrm{C}-\mathrm{C}$ bond for thermolysis and, as a result, methane is obtained as the main product of destruction [49]. In their work, $\mathrm{Li}$ et al. have indicated that one of the major challenges of microwave-assisted heating technology a is the composition of produced liquid and gases, where they have exposed heavy oil from one Chinese oil field to time variant microwave radiation until $18 \mathrm{~min}$. The experimental results illustrate that rapid increase in the gas flow rate was observed between 3 and 12 min radiation and, after 12 min radiation, this value tends to be constant. Moreover, experimental observations showed that the content of $\mathrm{C} 1-\mathrm{C} 4$ increases with radiation time. Nevertheless, the content of heavier components decreases, meanwhile the content of methane and ethane had a rapid increase from 9 to 12 min radiation [50].

The property of microwave energy is known to affect petroleum pitch with high sulfuric compounds content. Well, during hydrocracking, particles of petroleum pitch and steam or catalyst are thoroughly mixed with tar and the resulting mixture is exposed to microwave radiation in the presence of hydrogen [51].

In their work [52], Bely et al. authors have investigated the effect of high-intensity electric fields on individual hydrocarbons. It has been found that ion-molecular complex compounds form in the medium under study, which lead to a noticeable deterioration of the rheological properties of the system. In fact, an increase in the frequency of alternating current oscillations significantly affected the appearance of the rheological curve. In addition, the maximum viscosity has been fixed at low-frequency regions. From another hand, the C-C and C-H $\sigma$-bonds in hydrocarbon molecules have been lengthened under the action of alternating current, due to the polarization of the system as a whole with periodic deformations as well. As a result of the interference of deformations in the medium under study, an ultra-frequency resonance can occur, which is the cause of the destruction of hydrocarbon raw materials. Under the influence of alternating current, the intermolecular bonds of the complexes are destroyed, as a result of which energy is released and leads to the improvement of oil system rheological characteristics. The accumulation of aromatic hydrocarbons after treatment has also been noticeable, which can be explained by the destruction of higher molecular weight saturated hydrocarbons in a metastable state. In another work [53], authors have found that resins play the most significant role in the absorption of microwave field. Microwave radiation catalyst-induced dehydrogenation and hydrodesulfurization produce nearly $20 \%$ of hydrogen in the resulted gas. Therefore, it is possible to burn a part of the oil in place to enhance hydrodesulfurization reactions, by means of the produced hydrogen during THAI process application, for better oil upgrading. Furthermore, this could improve downhole hydrogen production, which can contribute to the efforts towards hydrogen economy [54].

Many researchers and experts have showed that microwave treatment could be used to increase catalytic conversion processes rates. Actually, such processes could be the light alkanes catalytic conversion, volatile organic compounds removal and air purification from sulfur- and nitrogen-containing compounds, in addition to the process of aromatic compounds hydrogenation and naphthenes dehydrogenation [55-59].

An increasing number of studies about microwave-assisted catalytic reactions including olefin hydrocarbons; principally ethylene, propylene and 1-pentene have established the participation of free radical intermediates, which, as a result, improved selected aliphatic and aromatic hydrocarbons conversion [60].

More recent evidence [61] on non-isothermal kinetics induced by microwave heating, particularly in terms of spatial distribution of temperature, has highlighted the possibility of 
localized superheating inducing by means of microwave heating and; therefore, increasing localized reaction rate.

In addition, other works have found out that EM heating is presenting an efficient energy source for decreasing the activation energies of both radical formation and recombination processes [62].

In fact, EM heating may reduce the viscosity of heavy oil because it targets, in the first place, the structure of resins and asphaltenes micelles. In their work [63], authors have examined the crude oil by combining analytical techniques of electrospray ionization and Fourier transform ion cyclotron resonance mass spectrometry (ESI FT-ICR MS). In which they found out that EM heating of crude oil with high content of oxygenated compounds may result in polymerization, thus increasing crude oil viscosity after microwave treatment. However, some cracking reactions may be associated to the microwave heating as well.

Ostapenko et al. [64] have studied and showed the effect of direct and alternating current on the rheological properties of oil-dispersed systems. The authors have concluded that different phenomena, such as electrophoresis and the emergence of a flow potential, are possible during the transportation of oil.

Several studies, for example, the work of Sheikh Ali et al. [65], have suggested that the alternative current energy is applied to destruct the oil dispersion system spatial grid. In fact, asphaltenes are polarizable components that make up the spatial structure. Under the action of an electric field, the excited activated complex radicals appear in the oil system, which reduce the activation energy of oxidation. These processes lead to a decrease in the structural and mechanical characteristics of oil systems.

The use of microwave treatment for heating reservoirs with low thermal conductivity and low permeability, containing low-mobile heavy oil or immobile natural bitumen, is one of the promising ways to create new and improve the existing technologies [66]. The content of light alkanes C10-C16 increases relatively to high-molecular homologues C23C29. In addition, there is a significant decrease in intensity of the high molecular weight region of the so-called naphthenic hump, reflecting the content of isoalkanes that undergo destruction (Figure 2) [67].

Rising global demand for energy and the decline in conventional light crude oil have sparked growing interest in heavy oil development. Nevertheless, heavy oil high viscosity creates operational, transportation and refining problems. In their work [63], authors have exposed crude oil samples from Sudan, China (Liaohe) and Venezuela to microwave irradiation in order to study the mechanisms of viscosity reduction. The SARA (saturates, aromatics, resins and asphaltenes) analysis of the associated samples was performed in accordance with the American Society for Testing and Materials, ASTM D4124-09. The SARA fractionation results have shown that microwave irradiation can affect the resin/asphaltene micellar structure leading to a change in the viscosity of the crude oil. Further studying of the crude oil was carried out by means of combined analytical electrospray ionization and Fourier transform ion cyclotron resonance mass spectrometry (ESI FT-ICR MS). The obtained data indicated that crude oils microwave irradiation with a high proportion of oxygenated compounds may result in polymerization and, ultimately, to an increase in the viscosity of crude oil after processing. However, sometimes cracking can take place because of microwave heating.

Actually, the crude oils containing nickel- and vanadium-based petroporphyrins may present a harmful effect on catalysts in the fluid catalytic cracking and hydrocracking residue, in addition to their processing. Nevertheless, the extraction and removal of nickel- and vanadium-based porphyrins from the crude oil is presenting a hard task to achieve. Lately, several experts and scientists have suggested the use of microwave approach to achieve a higher efficiency in removing $\mathrm{Ni}$ and $\mathrm{V}$ compounds from crude oil [68]. Thus, for better performance, it is necessary to understand the theory of the microwave demetalization mechanism (Figure 3). For this reason, several studies have studied the structure and properties of $\mathrm{Ni} / \mathrm{V}$ porphyrins by means of the density functional theory using the Becke Correlation Functional; Lee, Yang, Parr BLYP method. Indeed, 
the simulation has included different intensities and directions of the external applied electrica fields.

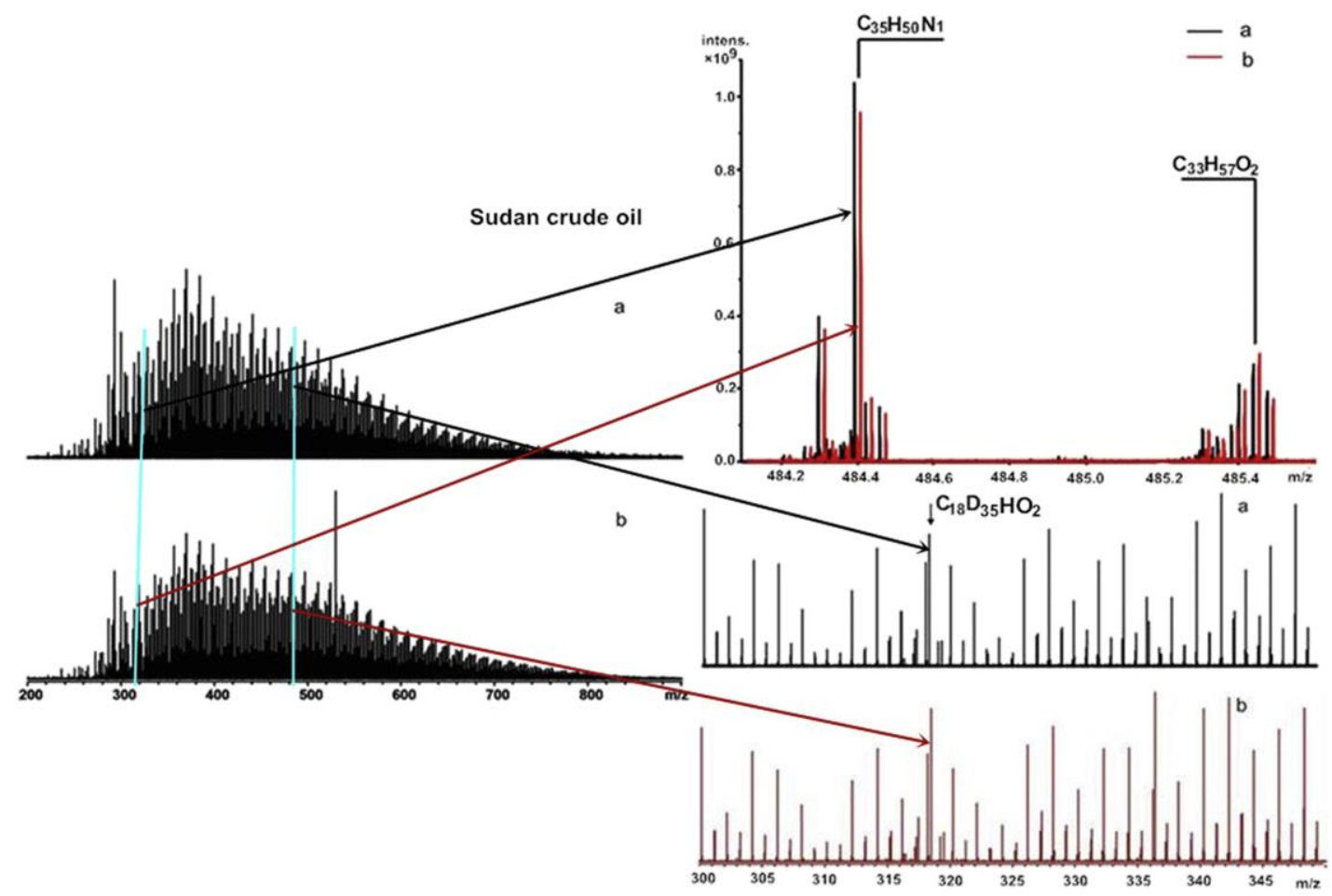

Figure 2. Negative ion Electrospray Ionization Fourier transform ion cyclotron (ESI FT-ICR) mass spectra of Sudan crude oil before and after microwave irradiation (left) and the segment enlarge mass spectra (right) (a: Crude oil; b: Crude oil after microwave). Reproduced with permission from [63], Copyright Elsevier, 2018.

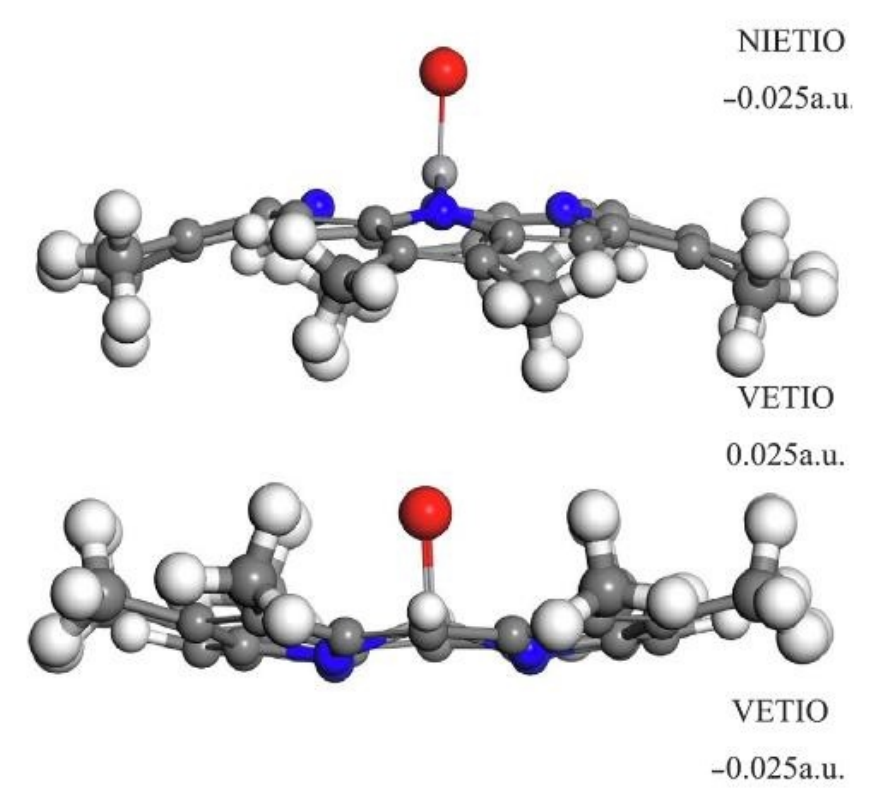

Figure 3. Molecular structures of vanadium porphyrin in the electric fields of 0.025 and 0.030 a.u. in the $\mathrm{z}$ direction. Reproduced with permission from [68], Copyright Elsevier, 2020.

The obtained results have shown that the best way of improving the pyrrole ring and $-\mathrm{CH}_{3}$ group activity is by the application of parallel electric field (Ex or E-x) and by whistling the vertical electric field (Ez or E-z), which mainly enhances metal atoms activity. It has been found as well that porphyrin ring deformation mode may be changed from 
dome to saddle mode at a vertical electric field larger than 0.025 a.u., with a remarkable decrease in the metal-N bond length. Therefore, the existence of an optimum microwave power in experiments is explained by the spatial structure deformation regularity [68].

The combination of microwave action and the use of heterogeneous catalysts provides a significant acceleration of chemical reactions. It is widely believed that using heterogeneous catalysts leads to increasing the efficiency of microwave treatment due to selective heating of the catalyst particles, which creates hot spots, resulting in an increased reaction rate [69].

The results of lignin microwave-assisted catalytic pyrolysis have showed a maximum yield of $33 \%$ and $36 \%$ for iron-containing catalyst samples and $45 \%$ for nickel-containing catalysts in an inert gas (argon) and a hydrogen-argon mixture mediums. The use of the chromatography-mass spectrometry (GC/MS) method has led to identify the liquid product fraction qualitative composition. In fact, the associated fraction is containing mainly phenol and anisol (i.e., derivatives of the monomeric units of lignin (coumaryl and coniferyl alcohols)). IR spectroscopy has been used for studying the probable sites of lignin surface functional groups' interaction with nickel and iron-containing nanoparticles [70].

In order to understand the desulfurization efficiency and its mechanism, it is necessary to understand the sulfide adsorption on the catalyst surface. Recent works [71] have applied the molecular dynamics and density functional theory calculations in order to shed light on the effect of microwave electric field on the adsorption of thiophene over different $\mathrm{MoS}_{2}$ nanocrystallites, in addition to studying the electronic distribution. It has been found that microwave field may possess a significant effect on adsorption position and configuration. Besides, it may strengthen the polarities of thiophene molecules and $\mathrm{MoS}_{2}$, which facilitates the thiophene C-S bon destruction. The induction of $\mathrm{S}$ component adsorption on active sites is mainly caused by the large charge loss of Mo atoms in a large area, which leads to a strong electrophilic effect after the generation of $S$ sites (Figure 4).

Potential adsorption is the main cause of modifying the hydrodesulphurization selectivity. Thiophene favors $\eta^{5}$ adsorption over multilayer dispersed $\mathrm{MoS}_{2}$ clusters under microwave field, inducing the hydrodesulphurization reactions to proceed along the hydrogenation mechanism [71].

In other works, authors have provided a general overview on microwave applications in petroleum oxidative desulfurization. The authors have concluded that milder reaction conditions could be used and higher petroleum oxidative desulfurization rate could be achieved under microwave treatment. Moreover, their work has indicated that microwave power level, treatment time, temperature, oxidizing agent dosage, microwave equipment and catalyst are the key operating factors influencing the petroleum oxidative desulfurization efficiency. They have found that the best removal rate was associated to diesel by $96 \%$. However, developing high efficiency, novel techniques and apparatuses are the main challenges facing sulfur removal from oils in industrial processes [72].

The efficiency of microwave treatment can be increased by injecting solvent into the reservoir. It is well known that EM heating with the use of solvents may lead to heavy oil dilution and, thereby, increasing its mobility. The latter can serve as a heat carrier by heat convection improving in porous media and; therefore, stimulating gravity drainage by the formation of a vapor chamber. Previous studies have designed new experimental setup for examining the performance of combining EM heating with solvent assisted gravity drainage enhanced heavy oil recovery. A series of lab experiments have been performed in order to investigate the performance and the mechanism of the associated method. The obtained results showed the efficiency of EM heating and solvent-assisted gravity drainage combination on enhancing heavy oil recovery. The authors have found that the recovery factors of EM heating only, alternate EM heating and n-hexane injection and alternate EM heating and n-octane injection were set to be $12.37 \%, 61.18 \%$ and $83.59 \%$, respectively. They have found out that initial water saturation increases the heating speed and provides a higher oil recovery. Moreover, the effect of solvent addition, affected by the solvent concentration in heavy oil, varies at different EM heating powers. Besides, the authors 
indicated that alternate EM heating and solvent injection is more cost effective due to the lower energy consumption and higher oil recovery compared to the simultaneous EM heating and solvent injection. In addition to this, the authors have established a lower content of asphaltenes in the recovered oil comparing to the initial one [73].
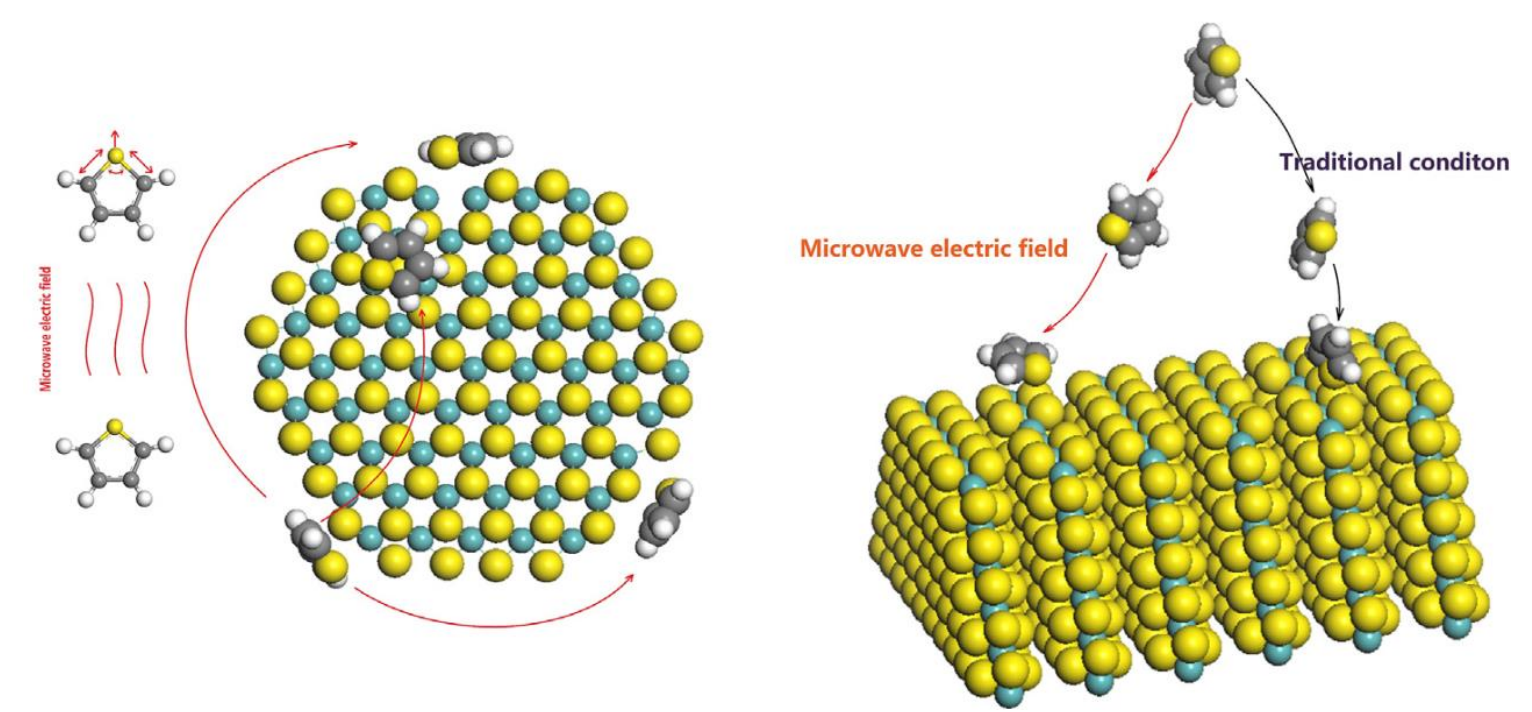

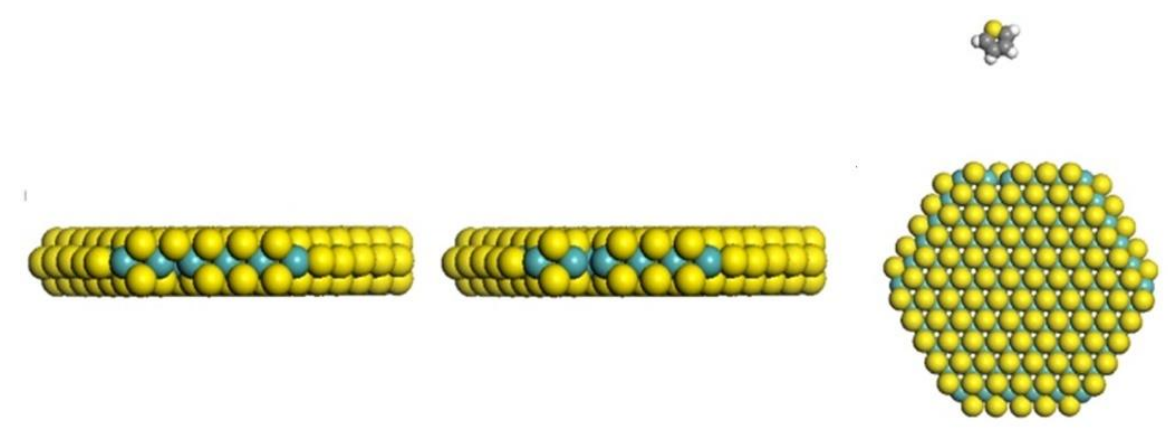

(a)

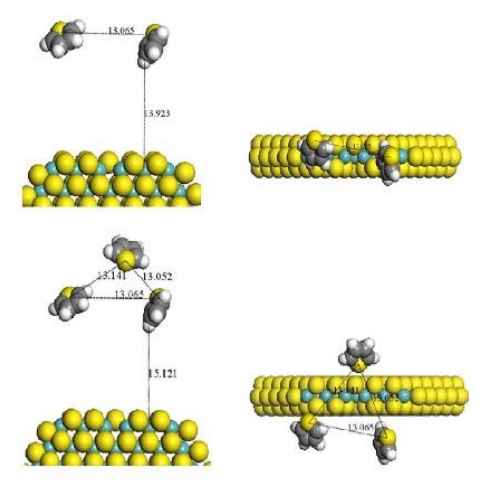

(c)

Figure 4. Adsorption model of (a) sulfur $\mathrm{S}$ and sulfur $2 \mathrm{~S}$ vacancies on the $\mathrm{MoS}_{2}$ cluster from the top view, (b) single thiophene adsorption; (c) two and three thiophene molecules adsorption. Reproduced with permission from [71], Copyright Elsevier, 2020.

EM heating is effective for the destruction of water-oil emulsions. The dispersion of dielectric parameters for water is observed in the frequency range 1-36 GHz. In addition to thermal heating, there is a decrease in the surface tension at the interface and the viscosity of the emulsion because of the polarization of polar molecules [74]. The existence of polar components in addition to their interactions within the emulsions maintain the stability of water in oil emulsions. In fact, asphaltenes, resins and water are the main polar components and the main reason of a high stable emulsion unable to break up unless more energy and chemical input is provided. Previous works have proposed an efficient method, which significantly decreases the required energy and chemical use, for the destruction of water in oil emulsion by means of microwave heating. Experiments have been conducted on different emulsions that originated from steam-assisted gravity drainage (SAGD) and expanding solvent SAGD (ES-SAGD). The aim was to investigate the effect of microwave heating on the polar components initially present in the emulsion. It has been expected that water would absorb mainly the microwave waves as being the main component in emulsions. However, the results reported in these works indicated that asphaltenes and resins absorb more microwave heating comparing to water molecules during emulsion breaking down [75]. 
In their work [76], Kovaleva et al. have showed the effect of a microwave electromagnetic heating on water-oil emulsions. The research results showed that the efficiency of emulsion stratification depends mainly on the strength properties of the armor shell. During microwave EM exposure to an oil-water emulsion, the main energy of the field was absorbed by the water phase concentrated in globules covered with an armoring shell. As a result, volumetric heat sources appear in the water globules, due to which their intense heating occurs, leading to the destruction of the armor shell. Lower temperatures are sufficient to rupture thin shells. For water globules with a more durable shell, the rupture temperature and pressure inside the shell can be so high that when the shell ruptures, a local rupture of the shell occurs and water is "injected" into the oil phase. As a result, a finely dispersed stable medium is formed. The authors propose to integrate the centrifugal force method to prevent local rupture.

In addition to the physical process of heating the medium by electromagnetic field, including the microwave range, chemical processes of transformation of high-molecular components (homolytic dissociation) are supposed to take place [77].

\section{Nanoparticles Perspectives Application for Enhanced Oil Recovery by Microwave Electromagnetic Heating}

Recently, nanoparticles with 1 to $100 \mathrm{~nm}$ diameter have been generating a growing interest in terms of enhancing heavy oil recovery. Actually, nanoparticle ability to change some reservoir characteristics and aspects can significantly improve the amount of heavy oil recovery from producing reservoirs [78]. A simple model was presented by Perry et al. estimating a temperature gradient in EM heating, of 1 and $100 \mathrm{~nm}$ metallic particles, typically found in supported metal catalyst structure. Both particles have limited case calculations of temperature increasing over a range of typical particle sizes. The proposed model was based on a simple steady-state energy balance, which utilizes the assumption stating that particles dissipate heat only to the gas-phase, and not the support matrix, which represents the best-case scenario for a temperature gradient relative to the surroundings. The model has showed that the temperature gradient is insignificant. This hypothesis has been further confirmed by an experiment in which the microwave-driven carbon monoxide reaction acts as an in situ temperature probe [79].

It has now been suggested that determining the potential for selective heating of metallic supported catalyst particles by means of microwaves in addition to highlighting other important parameters could be achieved by heat transfer analysis. Literally, based on the abovementioned estimates, selective heating appeared to be possible by means of microwave fields at high frequency heating catalyst beds cooled by gases at low pressures. It has been established, as well, that selective heating depends mainly on catalyst particle size at an optimum size in the range of 40 to $82 \mathrm{~nm}$. In addition to this, microwave frequency plays an important role in selective heating also [80]. A recent review on waste oil and metallic-char mixture heating characteristics during pyrolysis process, in addition to the metallic-char catalytic impact on pyrolysis products yield and characteristics, found that the porous metallic-char with high surface area $\left(124 \mathrm{~m}^{2} / \mathrm{g}\right)$ exhibits high thermal stability in $\mathrm{N}_{2}$ atmosphere. Besides, metals and metal oxides phases have been found to be attached or adsorbed on the char surface, which represents potential suitable catalysts for pyrolysis cracking reactions [81]. Due to magnetic properties exhibited by ferromagnetic nanoparticles comparing to bulk materials, these nanoparticles can be used as effective microwave absorbers. Some researchers have investigated the nanoparticles properties, their key material parameters and their single layer absorber characteristics. It has been found that high magnetic losses over a wide frequency range induce a series of strong and wide absorption peaks at higher frequencies. In fact, using metallic iron or cobalt nanoparticles may allow the creation of effective absorbers characterized by a low volume fraction of metallic elimination. In addition, authors have compared the nanocomposite absorbers characteristics (common dielectric or ferromagnetic absorbers) with identifying their potential advantages. The obtained results indicated that nanocomposites absorbers 
are crucial for the production of microwave and millimeter-wave absorbers because of their dielectric and ferromagnetic unique properties [82].

Zeolite effect on microwave processing of shale oil was investigated in a variety of works like the work of Neto et al. [83]. The authors have mixed oil shale with $5 \mathrm{wt} . \%$ BEA zeolite and heated the obtained sample, by microwave irradiation, in order to stimulate oil shale organic content conversion in the presence of acidic zeolite catalyst. The obtained data showed a decrease in the liquid products yield associated with an increase in coke amount. However, the gaseous and liquid products contained mainly lighter hydrocarbons in the presence of zeolites. Moreover, the authors have reported that microwave heating has stimulated the presence of aromatic compounds in the presence of zeolites as well.

Earlier works have reported the design of an orthogonal experiment where the designers have taken into account different proportions of iron oxide nanoparticles ( 0.1 , 0.5 , and $1 \mathrm{wt} . \%)$, different microwave output power $(600,800$, and $1000 \mathrm{~W})$ and different reaction temperatures $\left(550,750\right.$, and $\left.950^{\circ} \mathrm{C}\right)$. It has been found that microwave power in the presence of iron oxide at different concentrations affect the temperature distribution in the reaction medium, where iron oxide contributed in increasing shale oil temperature significantly at a short time. The authors have reported the useful advantages of utilizing microwave heating to increase temperature and improve higher quality oil yield instead of using traditional heating methods. In addition, the authors of the study have claimed the existence of more saturated and aromatic hydrocarbons in the oil obtained from microwave irradiation, with less sulfur and nitrogen compared to the oil obtained from classical heating. However, the best oil quality highest yield has been found in the presence of iron oxide nanoparticles at $0.1 \mathrm{wt} . \%$ at $800 \mathrm{~W}$ output power and $950{ }^{\circ} \mathrm{C}$. It is worthy to note that this study has highlighted the importance of microwave technology in enhancing unconventional oil resources recovery [84].

Actually, because of their growing interest in enhanced oil recovery application, Zhu et al. have investigated the effect of iron oxide nanoparticles on improving foamed pad fluid heating stimulation, in addition to reservoir potential damage after microwave heating coupled with hydraulic fracturing, for in-situ exploitation of oil shale [85]. Moreover, the authors have analyzed, as well, the obtained products from different heating rates by means of chromatograph-mass spectrometer, X-ray diffraction and scanning electron microscopy. Heating experiments indicated that foamed pad fluid was greater than waterbased pad fluid in terms of energy conservation. Moreover, it has been shown that iron oxide nanoparticles increase $75 \mathrm{~s}$ of the foamed pad fluid half time in addition to improving its viscosity. The study showed that iron oxide nanoparticles accomplish fast heating rate and energy saving, decrease the time by which oil shale may reach $750{ }^{\circ} \mathrm{C}$ at $1000 \mathrm{~W}$ to $10 \mathrm{~min}$ and show extremely low consumption of energy. The SEM analysis of this study [85] has showed that microwave heating induced pores and micro fractures formation. Besides, the retention of iron oxide nanoparticles inside the oil shale would not cause reservoir damage (Figure 5).

The analysis of the obtained products has led to conclude that reaction temperature and heating method had a great influence on the distribution of the non-condensable gases [85]. In their work, Nasri and authors have established a high efficiency of iron catalyst by upgrading the oil refinery vacuum distillation residue by using microwave irradiation at different catalyst dosages and different microwave power rates [86,87]. Many experts consider that microwave exposure in the presence of iron powder as a catalyst is directed to the processes of hydrodesulfurization of heavy and sulfur-containing crude oil. 

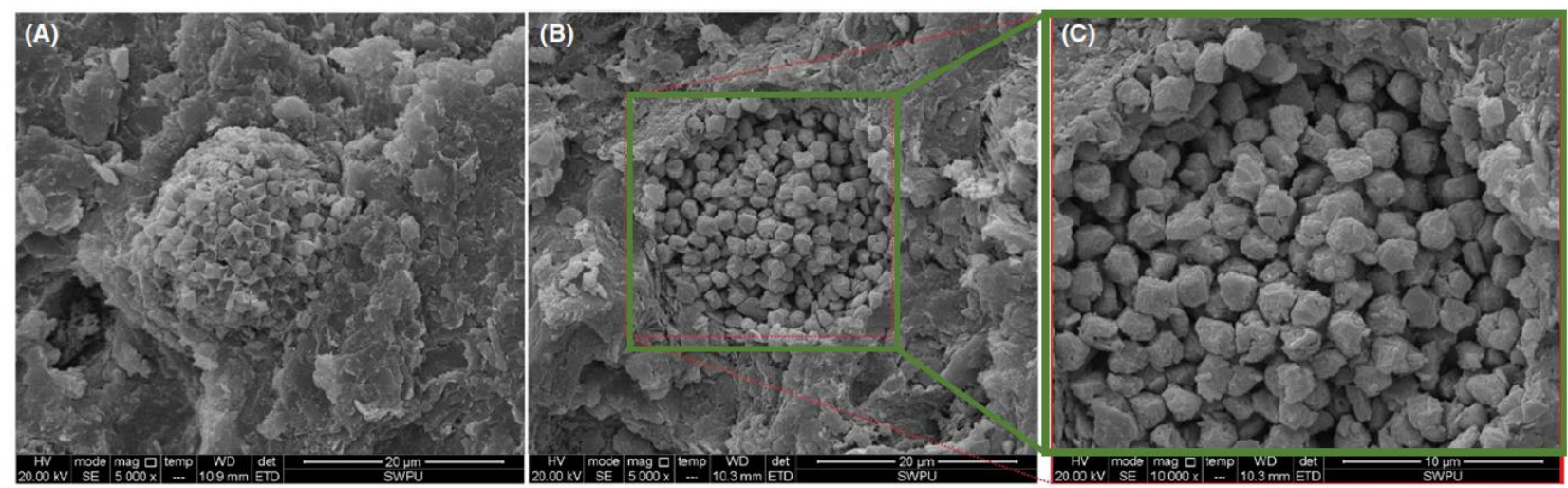

Figure 5. The component analysis of oil shale: (A) Origin morphology of pyrite, (B) morphology of pyrite after microwave heating with magnification lenses of $5000 \times$ and (C) morphology of pyrite after microwave heating with magnification lenses of $10,000 \times[85]$.

The ability to regulate microwave absorption properties is provided by the use of core-shell structures. For example, in the work provided by Yan et al. [88], $\mathrm{SiO}_{2} @ \mathrm{FeNi}_{3}$ core-shell structured submicrometer spheres, with $25 \mathrm{~nm}$ thick $\mathrm{SiO}_{2}$ shell, were obtained by means of a sol-gel process. The authors have achieved a significant enhancement of electromagnetic absorption performance by the silica coating over the range $2-18 \mathrm{GHz}$. In addition, the authors have obtained a reflection loss exceeding $-20 \mathrm{~dB}$ of the composite over the range $6.7-15.1 \mathrm{GHz}$ by choosing an appropriate sample thickness between 2.1 and $3.3 \mathrm{~mm}$. Moreover, an optimal reflection loss of $-61.3 \mathrm{~dB}$ was obtained as well at $8.7 \mathrm{GHz}$ with a thin absorber thickness of $2.9 \mathrm{~mm}$. The obtained results from this study indicate that coating the dielectric silica shell significantly improves the performance because of the stimulation of interface polarization at the alloys and dielectric interfaces [88]. In other work, direct application of $\mathrm{Ni}$ and Mo nanoparticles on Athabasca pyrolysis have showed that the $\mathrm{NiMo} / \mathrm{Al}_{2} \mathrm{O}_{3} / \mathrm{SiC}$ catalyst enhances the process performance [89].

The high electromagnetic wave absorption performance by ferromagnetic-dielectric nanocomposites distinguishes them among other metals because of their synergetic effects between different components. Some works have reported the design of core-shell structured $\mathrm{Co}_{7} \mathrm{Fe}_{3} @ \mathrm{TiO}_{2}$ composite particles that are subsequently annealed in $\mathrm{H}_{2} / \mathrm{Ar}$ atmosphere to further improve electromagnetic wave absorption performance. It has been established that introducing a $\mathrm{TiO}_{2}$ dielectric shell together with hydrogen annealing improves the electromagnetic properties, because of the increased conductivity and stimulated ferromagnetic resonance. It has been shown, as well, that using $\mathrm{Co}_{7} \mathrm{Fe}_{3} @ \mathrm{TiO}_{2}$ as absorbent results in an excellent electromagnetic wave absorption performance at $\mathrm{S}(2-4 \mathrm{GHz})$ and $\mathrm{C}(4-8 \mathrm{GHz})$ bands in coatings. In addition, it has been shown that electromagnetic wave absorption band location can be tailored in a wide range through regulating the coating thickness. In fact, effective absorption bands of $2.0 \mathrm{GHz}$ in the $\mathrm{C}$ band, at a thickness of $2.62 \mathrm{~mm}$, and of $1.7 \mathrm{GHz}$ in the $\mathrm{S}$ band, at thicknesses of $4.0-5.0 \mathrm{~mm}$, have been obtained. It has been concluded that the excellent electromagnetic properties are ascribed to the effective complementary between dielectric loss and ferromagnetic loss [90].

In a wide range of literatures, scientists report the important role played by microwave heating, when it comes to catalytic ways of decomposing viscous hydrocarbon compounds contained in heavy oil, for a better extraction of economically useful organic compounds such as C2 and C3 hydrocarbons. In fact, it is reported that adding water to tar sand material prior to reaction may contribute to its separation from sand, in addition to stimulating the formation of oxygenated hydrocarbon products [91].

Previous works have showed that pyrite in oil shale has a great influence on kerogen conversion during microwave processing. In fact, considerable tension could be caused by the expansion of pyrite, which may lead to tensile failures in shale samples, as shown by the experimental observations. Actually, the induced tensile stress could be lowered 
by confinement, which, by increasing electromagnetic heating power, may lead to it being overcome [92]. The results obtained during the framework of Schieck et al. were compared to previously obtained results about natural crystals. The authors have fixed conductivity between 0.05 and $3.5(\Omega \mathrm{cm})^{-1}$ and carrier concentration between $6.9 \times 10^{15}$ and $5.4 \times 10^{17} \mathrm{~cm}^{-3}$ using their measurements. It has been found that the peak mobility values range from 100 to $2000 \mathrm{~cm}^{2} /$ Vs. Moreover, the authors showed that sulfur deficiency and a number of impurity elements, such as $\mathrm{Si}, \mathrm{Cu}$ and $\mathrm{Al}$, can qualitatively account for the trends in the electronic properties [93].

In their work [94], Zhu and co-authors have analyzed and visualized oil shale microstructure under microwave heating at different heating rates by means of two-dimensional (optical microscope and scanning electron microscope) and advanced three-dimensional (micro-CT) methods. The volumetric reconstruction of initial shale oil and the sample treated by microwave heating has been completed for direct visualization of the pore structure and fracture network. The authors have investigated, as well, the similarities and differences between microwave heating and conventional heating. The obtained results have shown a significant change porosity and anisotropy degree of the samples under study.

Microwave heating results in more pores and fractures because of the differential thermal stress resulting from rapid heating, unlike conventional heating, as shown by traditional two-dimensional imaging methods. According to calculations of porosity based on the CT image data, long heating time and a high output power may result in a large porosity value. In fact, a largest porosity with a lowest pore heterogeneity distribution after heating have been illustrated by oil shale obtained by drilling horizontally into the bedding plane, which also showed a different fracture morphology (Figure 6). The obtained results have been claimed to be significant for shale oil exploitation by means of microwave heating. The authors also state that the application of the proposed techniques could be advantageous during products' transformation behavior evaluation [94].

\section{Induced porosity}

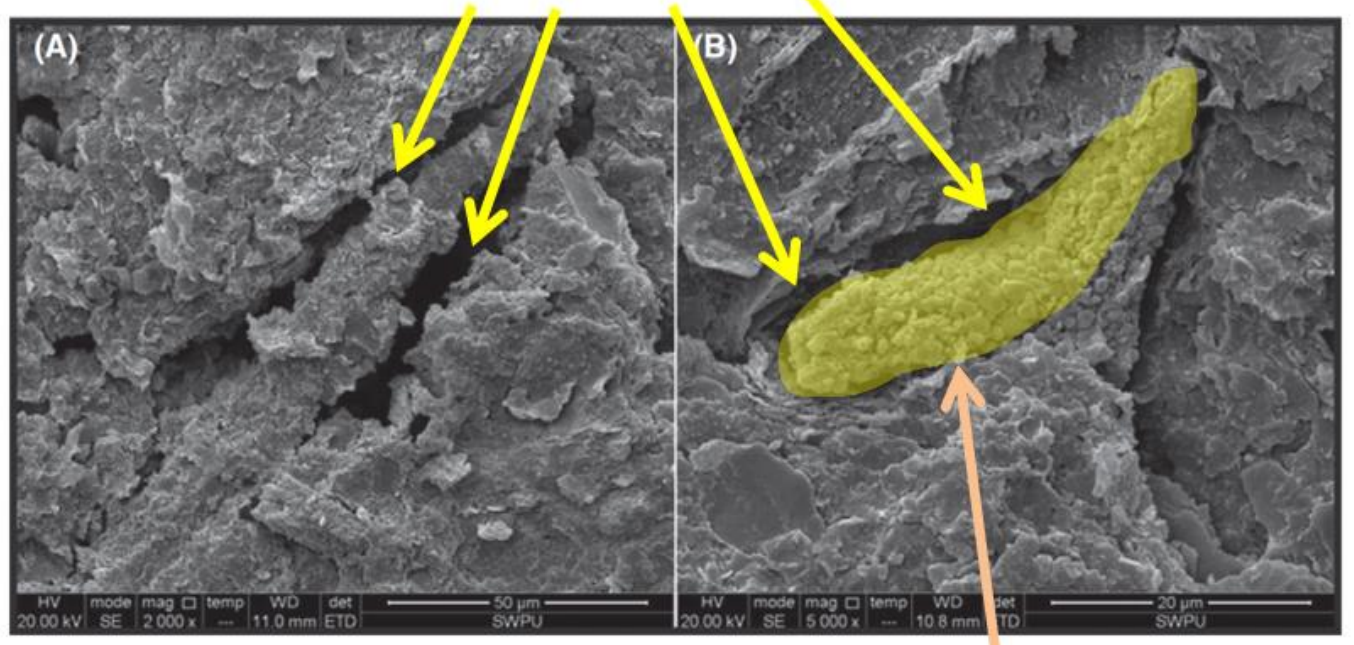

\section{The inclusion of pyrite}

Figure 6. SEM images of the oil shale after microwave irradiation: (A) fracture generation after microwave heating; (B) morphology of pyrite after microwave heating [94].

Various studies [95] have been performed on the effect of microwave radiation on the liquid-phase thermolysis of oil samples' heavy components in the presence of heterogeneous catalysts (magnetite and aluminum oxide). These catalysts intensively absorb the microwave electromagnetic field energy and transform it into heat. It has been shown that the introduction of catalytic additives into oil samples leads to a high level of microwave 
energy absorption. Besides, these catalytic systems transform the absorbed energy into heat which stimulate dielectric losses and; therefore, the efficiency of their heating. It is noteworthy that nanoparticles of transition metals are good absorbers of microwave radiation, which allows for the effect on heavy oil to be intensified.

In similar works, authors have used $\mathrm{Ni}$ and Fe nanoparticles with an oil and silica bead mixture and exposed them to EM heating. This work ended up with improving the yield efficiency and increasing heating rate. In other words, the obtained results witnessed a significant viscosity reduction. The same experiments have been repeated using high clay content as a shale reservoir model with the application of EM heating. The results of experiments have showed a rise in temperature (up to $\sim 200{ }^{\circ} \mathrm{C}$ ) in the presence of $\mathrm{Ni}$ nanoparticles. This temperature increment has resulted in higher oil recovery $(\sim 30 \%$ of OOIP). This study has highlighted the perspectives of EM heating application as an alternative to aqueous heating [96].

In their work, Al-farsi et al. have studied the effect of gamma alumina $\left(\gamma-\mathrm{Al}_{2} \mathrm{O}_{3}\right)$ and titanium (IV) oxide $\left(\mathrm{TiO}_{2}\right)$ nanoparticles at different concentrations on oil recovery. However, the authors have studied, as well, the effect of water saturation on the oil recovery and the influence of nanoparticles on the emulsion viscosity and the thermal conductivity of distilled water. The evidence from this study shows that when water saturation increases, the oil recovery increases, with optimum recovery occurring at a water saturation of $30 \%$. Nevertheless, using the microwave-heating application has highlighted a greater oil recovery than that from conventional heating. Moreover, it has been established that each type of nanoparticle $\left(\gamma-\mathrm{Al}_{2} \mathrm{O}_{3}\right.$ and $\left.\mathrm{TiO}_{2}\right)$ differently affects the emulsion viscosity or the water thermal conductivity because of various physical properties of each nanoparticle, such as shape and size. In fact, $\mathrm{Al}_{2} \mathrm{O}_{3}$ and $\mathrm{TiO}_{2}$ nanoparticles showed the most significant effect on oil recovery at low concentrations of 0.1 and $0.05 \mathrm{wt} . \%$, respectively. This study showed the perspectives of using nanotechnology for improving and overcoming the challenges of thermal EOR methods, especially the unconventional methods [97].

Other works have proposed $\mathrm{ZnO}$ nanoparticles for EOR because of their high melting point and thermal properties. In addition, these nanoparticles are able to polarize under electromagnetic heating; therefore, providing an innovative smart Nano-EOR process, denoted as EM-Assisted Nano-EOR. These studies have investigated the oil recovery mechanism under EM heating, such as reducing mobility ratio, lowering interfacial tensions and altering wettability. The obtained results showed that IFT reduction plays an important role in the oil recovery mechanism, especially in the presence of nanoparticles under EM heating, as compared to oil recovery by means of conventional heating. These results revealed the potential perspectives of utilizing water-based $\mathrm{ZnO}$ nanofluids for enhanced oil recovery purposes at a relatively high reservoir temperature [98].

Nanoparticles of iron oxide, titanium oxide and activated carbon, at certain parameters of microwave radiation, provide the chemical conversion of asphaltenes (Figure 7). This leads to an irreversible decrease in oil viscosity [99].

Literally, the presence of metal nanoparticles causes carbon-sulfur bonds to break within asphaltenes, which leads to an increase in saturated and aromatic hydrocarbons and a decrease in asphaltenes content. Thus, the viscosity of heavy oil and bitumen decreases significantly because of the decreasing average molecular weight. However, the obtained effect could be significantly improved in the presence of a strong hydrogen donor, which can be completely inhibited by the removal of all hydrogen donors. Nevertheless, the application of strong hydrogen donors in-situ presents a hard and an expensive method. Thereby, it is well recommended to create hydrogen donors in-situ within oil, rather than introducing them from an external source. Greff and Babadagli studied the EM heating effect on heavy oil recovery from sand pack by using a $2.45 \mathrm{GHz}$ emitter. During their work, they heated heavy oil samples at different heating rates in the presence and absence of a nanosize nickel catalyst. The authors found that nickel nanoparticles improve heavy oil recovery during EM heating, comparing to their absence, because of the intensification of the cracking and vaporization processes [100]. 


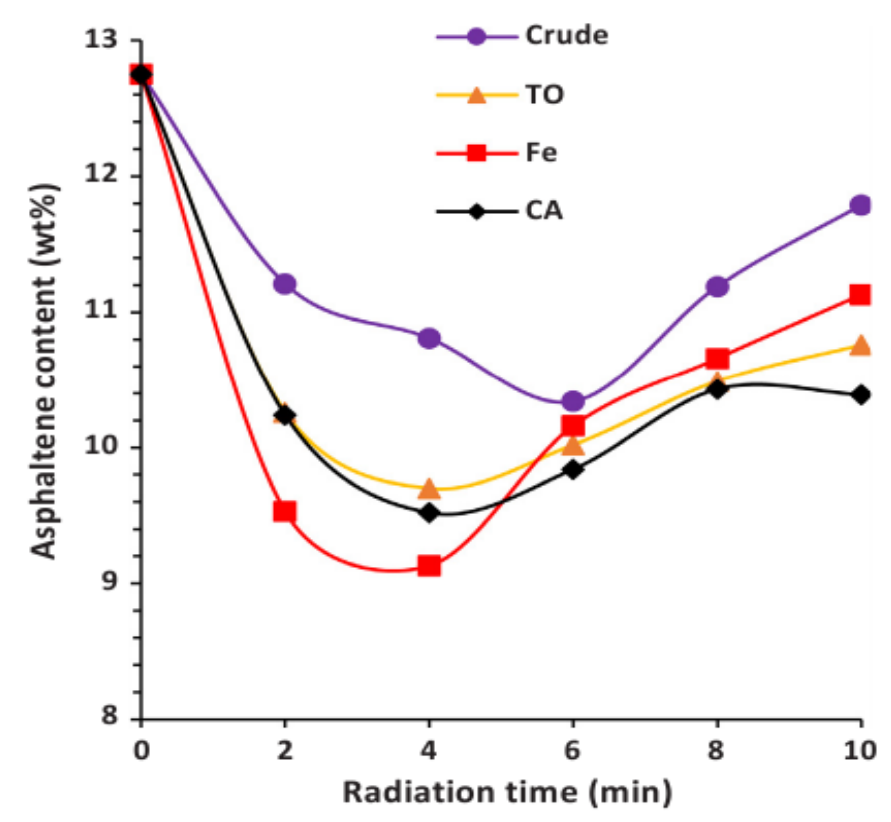

Figure 7. Content of asphaltenes variation in relation to radiation time. Reproduced with permission from [99], Copyright Elsevier, 2018.

It has been shown that using nanodispersed carbon during EM heating of oil for $1 \mathrm{~h}$ may lead to a deep conversion of heavy oil components at the low temperature of $150{ }^{\circ} \mathrm{C}$. This effect is achieved because of the non-thermal effect of microwave radiation in the presence of catalysts of a certain morphology and dispersion, in addition to hydrogen donor presence [101].

Lam et al. have investigated the pyrolysis of waste palm cooking oil (a widely used cooking oil in Asia) by means of EM heating in the presence of a well-mixed bed of activated carbon. In fact, this activated carbon was used, on the one hand, as a microwave absorber and, on the other hand, as a reaction bed. It was found that the carbon bed provided rapid heating $\left(\sim 18^{\circ} \mathrm{C} / \mathrm{min}\right)$ and a localized reaction hot zone. In fact, this zone thermally promoted extensive pyrolysis cracking of the oil waste at $450{ }^{\circ} \mathrm{C}$. The result was an enhanced biofuel product in a period of less than $25 \mathrm{~min}$ [102].

\section{Concluding Remarks}

The evidence from this review points toward the idea that the electromagnetic heating effect on the conversion of various hydrocarbon raw materials has merit and a potential wide application in terms of transportation and processing. Moreover, this review would seem to suggest that coupling microwave heating to different catalytic agents may have prospective implications, not only for in-situ enhanced oil recovery, but also for industrial refining processes. What is more, these findings would widen our knowledge about the use of microwave radiation in conjunction with transition metal catalysts for the development of unconventional hydrocarbon reserves.

Regardless, the fact that in-situ EM heating of heavy oil and shale oil in the presence of transition metals has been poorly studied and their absorption of microwave radiation has not yet been clarified, we believe that EM heating of reservoir zones coupled with aquathermolysis catalysts will enhance heavy oil and shale oil recovery and will ensure longer reservoir exploitation.

We are confident that our research will serve as a base for future studies in the following areas:

- The role of catalytic particles in absorbing microwave field energy;

- Studying the effect of particle dispersion on the process of microwave radiation conversion into thermal energy; 
- Investigation of the electromagnetic field's electric and magnetic components influence on the chemical transformation process of hydrocarbons;

- Developing efficient methods for injection of catalyst particles into the reservoir, such as injection through oil-soluble precursors which, in this case, allows for a significant catalyst dispersion throughout the reaction medium. Therefore, understanding the mechanism of in-situ formation of nanoparticles, as a result of oil-soluble catalyst precursor decomposition into a reservoir porous medium, under the influence of microwave heating would help us to understand and develop new innovative methods for enhancing unconventional oil recovery.

Author Contributions: Conceptualization, A.V.V. and M.R.G.; methodology, A.R.N. and T.O.K.; investigation A.T., A.A.P. and S.A.K.; data curation O.V.S. and K.A.S.; writing-original draft preparation, M.A.K.; writing-review and editing, O.G.M. and M.Y.G. All authors have read and agreed to the published version of the manuscript.

Funding: This research received no external funding.

Institutional Review Board Statement: Not applicable.

Informed Consent Statement: Not applicable.

Data Availability Statement: Data sharing not applicable.

Acknowledgments: This work was supported by the Ministry of Science and Higher Education of the Russian Federation under agreement NO 075-15-2020-931 within the framework of the development program for a world-class Research Center "Efficient development of the global liquid hydrocarbon reserves".

Conflicts of Interest: The authors declare no conflict of interest.

\section{References}

1. Jiang, S.; Liu, X.; Oilfield, L.; Liu, Y.; Zhong, L. In Situ upgrading heavy oil by aquathermolytic treatment under steam injection conditions. In Proceedings of the SPE International Symposium on Oilfield Chemistry, The Woodlands, TX, USA, 2-4 February 2005; Society of Petroleum Engineers: Richardson, TX, USA, 2005; pp. 1-8.

2. Montgomery, W.; Court, R.W.; Rees, A.C.; Sephton, M.A. High temperature reactions of water with heavy oil and bitumen: Insights into aquathermolysis chemistry during steam-assisted recovery. Fuel 2013, 113, 426-434. [CrossRef]

3. Elahi, S.M.; Scott, C.E.; Chen, Z.; Pereira-Almao, P. In-situ upgrading and enhanced recovery of heavy oil from carbonate reservoirs using nano-catalysts: Upgrading reactions analysis. Fuel 2019, 252, 262-271. [CrossRef]

4. Lin, R.; Chen, K.; Miao, M.; Zhang, L.; Wang, X.; Jiang, Y.; Zhang, J.; Wang, Y.; Pan, H. Reaction Mechanism of H2S Generation during Tetrahydrothiophene Aquathermolysis Reaction. Energy Fuels 2020, 34, 2781-2789. [CrossRef]

5. Maity, S.K.; Ancheyta, J.; Marroquín, G. Catalytic aquathermolysis used for viscosity reduction of heavy crude oils: A review. Energy Fuels 2010, 24, 2809-2816. [CrossRef]

6. Korneev, D.S.; Pevneva, G.S.; Golovko, A.K. Thermal Transformations of Asphaltenes at a Temperature of 120 C. J. Sib. Fed. Univ. Chem. 2019, 12, 101-117.

7. Gafurov, M.R.; Volodin, M.A.; Rodionov, A.A.; Sorokina, A.T.; Dolomatov, M.Y.; Petrov, A.V.; Vakhin, A.V.; Mamin, G.V.; Orlinskii, S.B. EPR study of spectra transformations of the intrinsic vanadyl-porphyrin complexes in heavy crude oils with temperature to probe the asphaltenes' aggregation. J. Pet. Sci. Eng. 2018, 166, 363-368. [CrossRef]

8. Sitnov, S.A.; Vakhin, A.V.; Mukhamatdinov, I.I.; Onishchenko, Y.V.; Feoktistov, D.A. Effects of calcite and dolomite on conversion of heavy oil under subcritical condition. Pet. Sci. Technol. 2019, 37, 687-693. [CrossRef]

9. Khelkhal, M.A.; Eskin, A.A.; Mukhamatdinov, I.I.; Feoktistov, D.A.; Vakhin, A.V. Comparative Kinetic Study on Heavy Oil Oxidation in the Presence of Nickel Tallate and Cobalt Tallate. Energy Fuels 2019, 33, 9107-9113. [CrossRef]

10. Mukhamatdinov, I.I.; Salih, I.S.S.; Rakhmatullin, I.Z.; Sitnov, S.A.; Laikov, A.V.; Klochkov, V.V.; Vakhin, A.V. Influence of Co-based catalyst on subfractional composition of heavy oil asphaltenes during aquathermolysis. J. Pet. Sci. Eng. 2020, $186,106721$. [CrossRef]

11. Muraza, O.; Galadima, A. Aquathermolysis of heavy oil: A review and perspective on catalyst development. Fuel 2015, 157, 219-231. [CrossRef]

12. Al-Muntaser, A.A.; Varfolomeev, M.A.; Suwaid, M.A.; Feoktistov, D.A.; Yuan, C.; Klimovitskii, A.E.; Gareev, B.I.; Djimasbe, R.; Nurgaliev, D.K.; Kudryashov, S.I.; et al. Hydrogen donating capacity of water in catalytic and non-catalytic aquathermolysis of extra-heavy oil: Deuterium tracing study. Fuel 2021, 283, 118957. [CrossRef] 
13. Khelkhal, M.A.; Eskin, A.A.; Nurgaliev, D.K.; Vakhin, A.V. Thermal study on stabilizing combustion front via bimetallic Mn@Cu tallates during heavy oil oxidation. In Proceedings of the 20th International Conference on Petroleum Phase Behavior \& Fouling (PetroPhase 2019), Kanazawa, Japan, 2-6 June 2019; p. 20.

14. Cao, Y.B.; Zhang, L.L.; Xia, D.H. Catalytic aquathermolysis of Shengli heavy crude oil with an amphiphilic cobalt catalyst. Pet. Sci. 2016, 13, 463-475. [CrossRef]

15. Vakhin, A.V.; Aliev, F.A.; Mukhamatdinov, I.I.; Sitnov, S.A.; Sharifullin, A.V.; Kudryashov, S.I.; Afanasiev, I.S.; Petrashov, O.V.; Nurgaliev, D.K. Catalytic aquathermolysis of boca de jaruco heavy oil with nickel-based oil-soluble catalyst. Processes $2020,8,532$. [CrossRef]

16. Mukhamatdinov, I.I.; Khaidarova, A.R.; Zaripova, R.D.; Mukhamatdinova, R.E.; Sitnov, S.A.; Vakhin, A.V. The composition and structure of ultra-dispersed mixed oxide (Ii, iii) particles and their influence on in-situ conversion of heavy oil. Catalysts 2020, 10, 114. [CrossRef]

17. Kayukova, G.P.; Mikhailova, A.N.; Kosachev, I.P.; Feoktistov, D.A.; Vakhin, A.V. Conversion of Heavy Oil with Different Chemical Compositions under Catalytic Aquathermolysis with an Amphiphilic Fe-Co-Cu Catalyst and Kaolin. Energy Fuels 2018, 32, 6488-6497. [CrossRef]

18. Yusuf, A.; Al-Hajri, R.S.; Al-Waheibi, Y.M.; Jibril, B.Y. In-situ upgrading of Omani heavy oil with catalyst and hydrogen donor. J. Anal. Appl. Pyrolysis 2016, 121, 102-112. [CrossRef]

19. Nassar, N.N.; Husein, M.M. Ultradispersed particles in heavy oil: Part I, preparation and stabilization of iron oxide/hydroxide. Fuel Process. Technol. 2010, 91, 164-168. [CrossRef]

20. Leite, L.F.; Borschiver, S.; Canongia, C.; Antunes, A.M.S. Survey of microwave technology potential application in heavy crude oil upgrading. In Proceedings of the 2nd Mercosur Congress on Chemical Engineering and 4th Mercosur Congress on Process Systems Engineering, Rio de Janeiro, Brazil, 14-18 August 2005.

21. Mokhlisse, A.; Chanâa, M.B.; Outzourhit, A. Pyrolysis of the Moroccan (Tarfaya) oil shales under microwave irradiation. Fuel 2000, 79, 733-742.

22. Gunal, O.G.; Islam, M.R. Alteration of asphaltic crude rheology with electromagnetic and ultrasonic irradiation. J. Pet. Sci. Eng. 2000, 26, 263-272. [CrossRef]

23. Ethaib, S.; Omar, R.; Kamal, S.M.M.; Awang Biak, D.R.; Zubaidi, S.L. Microwave-assisted pyrolysis of biomass waste: A mini review. Processes 2020, 8, 1190. [CrossRef]

24. Franus, M.; Panek, R.; Madej, J.; Franus, W. The properties of fly ash derived lightweight aggregates obtained using microwave radiation. Constr. Build. Mater. 2019, 227, 116677. [CrossRef]

25. Ghasemi, H.; Mozaffari, S.; Mousavi, S.H.; Aghabarari, B.; Abu-Zahra, N. Decolorization of wastewater by heterogeneous Fenton reaction using $\mathrm{MnO} 2-\mathrm{Fe} 3 \mathrm{O} 4 / \mathrm{CuO}$ hybrid catalysts. J. Environ. Chem. Eng. 2021, 105091. [CrossRef]

26. Ghasemi, H.; Aghabarari, B.; Alizadeh, M.; Khanlarkhani, A.; Abu-Zahra, N. High efficiency decolorization of wastewater by Fenton catalyst: Magnetic iron-copper hybrid oxides. J. Water Process Eng. 2020, 37, 101540. [CrossRef]

27. Malinowski, S.; Presečki, I.; Jajčinović, I.; Brnardić, I.; Mandić, V.; Grčić, I. Intensification of Dihydroxybenzenes Degradation over Immobilized TiO2 Based Photocatalysts under Simulated Solar Light. Appl. Sci. 2020, 10, 7571. [CrossRef]

28. Sajid, M.; Ayoub, M.; Yusup, S.; Abdullah, B.; Shamsuddin, R.; Bilad, R.; Chong, C.C.; Aqsha, A. Short-Chain Polyglycerol Production via Microwave-Assisted Solventless Glycerol Polymerization Process Over Lioh-Modified Aluminium Pillared Clay Catalyst: Parametric Study. Processes 2020, 8, 1093. [CrossRef]

29. Cheng, G.; Li, Y.; Sun, L.; Luo, S.; Kyzas, G.Z.; Fu, J. Residue Char Derived from Microwave-Assisted Pyrolysis of Sludge as Adsorbent for the Removal of Methylene Blue from Aqueous Solutions. Processes 2020, 8, 979. [CrossRef]

30. Khelfa, A.; Rodrigues, F.A.; Koubaa, M.; Vorobiev, E. Microwave-Assisted Pyrolysis of Pine Wood Sawdust Mixed with Activated Carbon for Bio-Oil and Bio-Char Production. Processes 2020, 8, 1437. [CrossRef]

31. Auwal, I.A.; Wong, K.-L.; Ling, T.C.; Ooi, B.S.; Ng, E.-P. Metal Chlorides Grafted on SAPO-5 (MClx/SAPO-5) as Reusable and Superior Catalysts for Acylation of 2-Methylfuran Under Non-Microwave Instant Heating Condition. Processes 2020, 8, 603. [CrossRef]

32. Mozaffari, S.; Li, W.; Thompson, C.; Ivanov, S.; Seifert, S.; Lee, B.; Kovarik, L.; Karim, A.M. Colloidal nanoparticle size control: Experimental and kinetic modeling investigation of the ligand-metal binding role in controlling the nucleation and growth kinetics. Nanoscale 2017, 9, 13772-13785. [CrossRef] [PubMed]

33. Stefanidis, G.D.; Muñoz, A.N.; Sturm, G.S.J.; Stankiewicz, A. A helicopter view of microwave application to chemical processes: Reactions, separations, and equipment concepts. Rev. Chem. Eng. 2014, 30, 233-259. [CrossRef]

34. Buchachenko, A.L.; Frankevich, E.L. Chemical Generation and Reception of Radio-And Microwaves; John Wiley \& Sons: Hoboken, NJ, USA, 1993; ISBN 047118859X.

35. Buchachenko, A.L.; Berdinskii, V.L. Chemically induced radio-frequency emission and chemical radiophysics. Russ. Chem. Rev. 1983, 52, 1. [CrossRef]

36. Berlinsky, V.; Yasina, L.L.; Buchachenko, A. Microwave magnetic isotope effect. Theory. Chem. Phys. $2005,24,35-41$.

37. Menéndez, J.A.; Juárez-Pérez, E.J.; Ruisánchez, E.; Bermúdez, J.M.; Arenillas, A. Ball lightning plasma and plasma arc formation during the microwave heating of carbons. Carbon N. Y. 2011, 49, 346-349. [CrossRef] 
38. Horikoshi, S.; Kamata, M.; Mitani, T.; Serpone, N. Control of microwave-generated hot spots. 6. Generation of hot spots in dispersed catalyst particulates and factors that affect catalyzed organic syntheses in heterogeneous media. Ind. Eng. Chem. Res. 2014, 53, 14941-14947. [CrossRef]

39. Horikoshi, S.; Osawa, A.; Sakamoto, S.; Serpone, N. Control of microwave-generated hot spots. Part V. Mechanisms of hot-spot generation and aggregation of catalyst in a microwave-assisted reaction in toluene catalyzed by Pd-loaded AC particulates. Appl. Catal. A Gen. 2013, 460, 52-60. [CrossRef]

40. Xu, W.; Zhou, J.; Su, Z.; Ou, Y.; You, Z. Microwave catalytic effect: A new exact reason for microwave-driven heterogeneous gas-phase catalytic reactions. Catal. Sci. Technol. 2016, 6, 698-702. [CrossRef]

41. Zhou, J.; You, Z.; Xu, W.; Su, Z.; Qiu, Y.; Gao, L.; Yin, C.; Lan, L. Microwave irradiation directly excites semiconductor catalyst to produce electric current or electron-holes pairs. Sci. Rep. 2019, 9, 1-7.

42. Zhang, X.; Hayward, D.O.; Mingos, D.M.P. Effects of microwave dielectric heating on heterogeneous catalysis. Catal. Lett. 2003, 88, 33-38. [CrossRef]

43. Wong, G.K.; Yen, T.F. An electron spin resonance probe method for the understanding of petroleum asphaltene macrostructure. J. Pet. Sci. Eng. 2000, 28, 55-64. [CrossRef]

44. Liu, F.; Darjani, S.; Akhmetkhanova, N.; Maldarelli, C.; Banerjee, S.; Pauchard, V. Mixture effect on the dilatation rheology of asphaltenes-laden interfaces. Langmuir 2017, 33, 1927-1942. [CrossRef] [PubMed]

45. Smirnov, V.P. Possibilities of electron-stimulated cracking of high-molecular compounds in the oil and gas industry. In Proceedings of the 3rd International Forum on Nanotechnologies, Moscow, Russia, 1-3 November 2010.

46. Maganov, R.; Sayakhov, F. High-frequency electromagnetic action for the recovery of high-viscosity heavy oils. Proc. High. Educ. Institutions. Oil Gas 2000, 45-51.

47. Burkin, K.E.; Akhmedyanova, R.; Liakumovich, A. One-step method for producing isoprene from trimethylcarbinol and 1, 3 , 5-trioxane on a cation-exchange resin using microwave radiation. Kazan Technol. Univ. Bull. 2013, 16, 568-572.

48. Kovaleva, L.A.; Zinnatullin, R.R.; Mullayanov, A.I.; Shrubkovskii, I.I. Experimental studies of heating rheologically complex fluids with electromagnetic field. High Temp. 2016, 54, 612-614. [CrossRef]

49. Tsodikov, M.V.; Konstantinov, G.I.; Chistyakov, A.V.; Arapova, O.V.; Perederii, M.A. Utilization of petroleum residues under microwave irradiation. Chem. Eng. J. 2016, 292, 315-320. [CrossRef]

50. Li, L.; Feng, H. Effect of microwave radiation time on the composition of gas produced from microwave assisted heavy oil upgrading. Pet. Sci. Technol. 2020, 38, 659-665. [CrossRef]

51. Salihov, K.M. 10 Lectures about Spin Chemistry; Unipress: Kazan, Russia, 2000.

52. White, O.; Iskanderov, Y.M.; Muramovich, V.; Tuev, S.; Anisimov, P. Molecular modification of liquid hydrocarbon fuels by electric fields. In Proceedings of the All-Russian Scientific and Practical Conference "Transport of Russia: Problems and prospects", St. Petersburg, Russia, 1-2 November 2010.

53. Zhang, Y.; Adam, M.; Hart, A.; Wood, J.; Rigby, S.P.; Robinson, J.P. Impact of Oil Composition on Microwave Heating Behavior of Heavy Oils. Energy Fuels 2018, 32, 1592-1599. [CrossRef]

54. Adam, M.; Hart, A.; Wood, J.; Robinson, J.P.; Rigby, S.P. Microwave-assisted Catalytic Upgrading of Heavy Oil. In Proceedings of the 4th North American Symposium for Chemical Reaction Engineering (NASCRE 4), Houston, TX, USA, 10-13 March 2019.

55. Gedye, R.; Smith, F.; Westaway, K.; Ali, H.; Baldisera, L. The use of microwave ovens for rapid organic synthesis. Tetrahedron Lett. 1986, 27, 279-282. [CrossRef]

56. Wan, J.K.S. Microwaves and chemistry: The catalysis of an exciting marriage. Res. Chem. Intermed. 1993, 19, 147. [CrossRef]

57. Cundy, C.S. Microwave techniques in the synthesis and modification of zeolite catalysts. A review. Collect. Czechoslov. Chem. Commun. 1998, 63, 1699-1723. [CrossRef]

58. Kustov, L.M.; Sinev, I.M. Microwave activation of catalysts and catalytic processes. Russ. J. Phys. Chem. A 2010, 84, 1676-1694. [CrossRef]

59. Hayward, D. Apparent equilibrium shifts and hot-spot formation for catalytic reactions induced by microwave dielectric heating. Chem. Commun. 1999, 975-976.

60. Cameron, K.L.; Depew, M.C.; Wan, J.K.S. Pulsed microwave catalytic decomposition of olefins. Res. Chem. Intermed. 1991, 16, 57-70. [CrossRef]

61. Stuerga, D.; Gaillard, P. Microwave heating as a new way to induce localized enhancements of reaction rate. Non-isothermal and heterogeneous kinetics. Tetrahedron 1996, 52, 5505-5510. [CrossRef]

62. Kim, D.-W.; Im, K.-K.; Kim, H.J.; Lee, D.H.; Kim, Y.A.; Choi, J.; Yang, K.S. Effects of electromagnetic irradiation on low-molecularweight fraction of fluidized catalytic cracking decant oil for synthesis of pitch precursor. J. Ind. Eng. Chem. 2020, 82, 205-210. [CrossRef]

63. Shang, H.; Yue, Y.; Zhang, J.; Wang, J.; Shi, Q.; Zhang, W.; Liu, L.; Omar, S. Effect of microwave irradiation on the viscosity of crude oil: A view at the molecular level. Fuel Process. Technol. 2018, 170, 44-52. [CrossRef]

64. Ostapenko, A. Electroviscous effect in an alternating electric field. Tech. Phys. J. 2000, 70, 136. [CrossRef]

65. Sheikh Ali, D. On the role of electrokinetic phenomena in the process of paraffin deposits during oil production. Nedra Mosc. 1965, 139-153.

66. Sayakhov, F.L.; Maganov, R.U.; Kovaleva, L.A. Application of electromagnetic influence in the production of high-viscosity oils. Izv. Univ. Oil Gas 1998, 1, 35-39. 
67. Hot, D.; Kayukova, G.; Nigmedzyanova, L.; Kiyamova, A.; Ganeeva, Y. Influence of microwave heating on the yield and composition of natural bitumen from sandstones of the Shugurovskoye field. In Proceedings of the Materials of the International Scientific and Practical Conference, Moscow, Russia, 1-3 November 2007; pp. 178-183.

68. Li, Y.; Shang, H.; Zhang, Q.; Elabyouki, M.; Zhang, W. Theoretical study of the structure and properties of Ni/V porphyrins under microwave electric field: A DFT study. Fuel 2020, 278, 118305. [CrossRef]

69. Chemat, F.; Esveld, D.C.; Poux, M.; Di-Martino, J.L. The Role of Selective Heating in the Microwave Activation of Heterogeneous Catmnsis Reactions Using a Continuous Microwave Reactor. J. Microw. Power Electromagn. Energy 1998, 33, 88-94. [CrossRef]

70. Arapova, O.V.; Chistyakov, A.V.; Palankoev, T.A.; Bondarenko, G.N.; Tsodikov, M.V. Microwave-Assisted Lignin Conversion to Liquid Products in the Presence of Iron and Nickel. Pet. Chem. 2020, 60, 1019-1025. [CrossRef]

71. Wang, T.; Shang, H.; Zhang, Q. Adsorption behavior of thiophene on MoS2 under a microwave electric field via DFT and MD studies. Chem. Eng. Sci. 2020, 228, 115950. [CrossRef]

72. Shang, H.; Zhang, H.; Du, W.; Liu, Z. Development of microwave assisted oxidative desulfurization of petroleum oils: A review. J. Ind. Eng. Chem. 2013, 19, 1426-1432. [CrossRef]

73. Hu, L.; Li, H.A.; Babadagli, T.; Ahmadloo, M. Experimental investigation of combined electromagnetic heating and solventassisted gravity drainage for heavy oil recovery. J. Pet. Sci. Eng. 2017, 154, 589-601. [CrossRef]

74. Kovaleva, L.A.; Zinnatullin, R.R.; Valeev, M.D.; Minnigalimov, R.Z.; Fassahov, R.H. Laboratory investigations of the heating of high-viscosity oil in pipelines by a high frequency electromagnetic field (Russian). Oil Ind. J. 2019, 2019, 82-85.

75. Kar, T.; Hascakir, B. The role of resins, asphaltenes, and water in water-oil emulsion breaking with microwave heating. Energy Fuels 2015, 29, 3684-3690. [CrossRef]

76. Kovaleva, L.; Zinnatullin, R.; Mullayanov, A.; Blagochinov, V.; Valiev, S.M. Investigation of the integrated effect of microwave electromagnetic radiation and the field of centrifugal forces on water-oil emulsions. In Proceedings of the XI All-Russian Congress on Fundamental Problems of Theoretical and Applied Mechanics, Kazan, Russia, 20-24 August 2015; pp. $1831-1833$.

77. Kovaleva, L.A.; Zinnatullin, R.R.; Sultanguzhin, R.F.; Shrubkovski, I.I.; Myasnikov, A.V. Experimental studies on heating oil-saturated rocks by electromagnetic field. High Temp. 2017, 55, 837-839. [CrossRef]

78. Aziz, H.; Tunio, S.Q. Enhancing oil recovery using nanoparticles-A review. Adv. Nat. Sci. Nanosci. Nanotechnol. 2019, 10, 33001. [CrossRef]

79. Perry, W.L.; Cooke, D.W.; Katz, J.D.; Datye, A.K. On the possibility of a significant temperature gradient in supported metal catalysts subjected to microwave heating. Catal. Lett. 1997, 47, 1-4. [CrossRef]

80. Thomas, J.R. Particle size effect in microwave-enhanced catalysis. Catal. Lett. 1997, 49, 137-141. [CrossRef]

81. Lam, S.S.; Liew, R.K.; Cheng, C.K.; Chase, H.A. Catalytic microwave pyrolysis of waste engine oil using metallic pyrolysis char. Appl. Catal. B Environ. 2015, 176, 601-617. [CrossRef]

82. Bregar, V.B. Advantages of ferromagnetic nanoparticle composites in microwave absorbers. IEEE Trans. Magn. 2004, 40, 1679-1684. [CrossRef]

83. Neto, A.; Thomas, S.; Bond, G.; Thibault-Starzyk, F.; Ribeiro, F.; Henriques, C. The oil shale transformation in the presence of an acidic BEA zeolite under microwave irradiation. Energy Fuels 2014, 28, 2365-2377. [CrossRef]

84. Yang, Z.; Zhu, J.; Li, X.; Luo, D.; Qi, S.; Jia, M. Experimental investigation of the transformation of oil shale with fracturing fluids under microwave heating in the presence of nanoparticles. Energy Fuels 2017, 31, 10348-10357. [CrossRef]

85. Zhu, J.; Yang, Z.; Li, X.; Qi, S.; Jia, M. Application of microwave heating with iron oxide nanoparticles in the in-situ exploitation of oil shale. Energy Sci. Eng. 2018, 6, 548-562. [CrossRef]

86. Nasri, Z. Upgrading vacuum distillation residue of oil refinery using microwave irradiation. Chem. Eng. Process. Intensif. 2019, 146, 107675. [CrossRef]

87. Nasri, Z.; Mozafari, M. Multivariable statistical analysis and optimization of Iranian heavy crude oil upgrading using microwave technology by response surface methodology (RSM). J. Pet. Sci. Eng. 2018, 161, 427-444. [CrossRef]

88. Yan, S.J.; Zhen, L.; Xu, C.Y.; Jiang, J.T.; Shao, W.Z. Microwave absorption properties of FeNi3 submicrometre spheres and SiO2@ FeNi3 core-shell structures. J. Phys. D Appl. Phys. 2010, 43, 245003. [CrossRef]

89. Jeon, S.G.; Kwak, N.S.; Rho, N.S.; Ko, C.H.; Na, J.-G.; Yi, K.B.; Park, S. Bin Catalytic pyrolysis of Athabasca bitumen in H2 atmosphere using microwave irradiation. Chem. Eng. Res. Des. 2012, 90, 1292-1296. [CrossRef]

90. Chen, N.; Jiang, J.-T.; Guan, Z.-J.; Yan, S.-J.; Zhen, L.; Xu, C.-Y. Designing Co 7 Fe $3 @$ TiO 2 Core-Shell Nanospheres for Electromagnetic Wave Absorption in S and C Bands. Electron. Mater. Lett. 2020, 16, 1-11. [CrossRef]

91. Depew, M.C.; Lem, S.; Wan, J.K.S. Microwve inducdd catalytic decomposition of some alberta oil sands and bitumens. Res. Chem. Intermed. 1991, 16, 213-223. [CrossRef]

92. Hu, L.; Li, H.; Babadagli, T.; Xie, X.; Deng, H. Thermal stimulation of shale formations by electromagnetic heating: A clean technique for enhancing oil and gas recovery. J. Clean. Prod. 2020, 277, 123197. [CrossRef]

93. Schieck, R.; Hartmann, A.; Fiechter, S.; Könenkamp, R.; Wetzel, H. Electrical properties of natural and synthetic pyrite (FeS 2) crystals. J. Mater. Res. 1990, 5, 1567-1572. [CrossRef]

94. Zhu, J.; Yang, Z.; Li, X.; Qi, S.; Fang, Q.; Ding, Y. The experimental study of microwave heating on the microstructure of oil shale samples. Energy Sci. Eng. 2019, 7, 809-820. [CrossRef]

95. Muradova, P.A.; Zulfugarova, S.M.; Graser, E.; Strekov, A.S.; Litvishkov, Y.N. Microwaves Induced Thermolysis of Petroleum under Contact with Heterogenous Catalysts. Chem. Ing. Tech. 2018, 90, 393-397. [CrossRef] 
96. Bera, A.; Babadagli, T. Effect of native and injected nano-particles on the efficiency of heavy oil recovery by radio frequency electromagnetic heating. J. Pet. Sci. Eng. 2017, 153, 244-256. [CrossRef]

97. Ramezanpour, M.; Siavashi, M. Application of SiO 2-water nanofluid to enhance oil recovery. J. Therm. Anal. Calorim. 2019, 135, 565-580. [CrossRef]

98. Adil, M.; Lee, K.; Mohd Zaid, H.; Ahmad Latiff, N.R.; Alnarabiji, M.S. Experimental study on electromagnetic-assisted ZnO nanofluid flooding for enhanced oil recovery (EOR). PLOS ONE 2018, 13, e0193518. [CrossRef]

99. Taheri-Shakib, J.; Shekarifard, A.; Naderi, H. Heavy crude oil upgrading using nanoparticles by applying electromagnetic technique. Fuel 2018, 232, 704-711. [CrossRef]

100. Greff, J.H.; Babadagli, T. Catalytic effects of nano-size metal ions in breaking asphaltene molecules during thermal recovery of heavy-oil. In Proceedings of the SPE Annual Technical Conference and Exhibition, Denver, CO, USA, 30 October-2 November 2011; Society of Petroleum Engineers: Richardson, TX, USA, 2011; Volume 3, pp. 1903-1912.

101. Li, K.; Hou, B.; Wang, L.; Cui, Y. Application of carbon nanocatalysts in upgrading heavy crude oil assisted with microwave heating. Nano Lett. 2014, 14, 3002-3008. [CrossRef] [PubMed]

102. Lam, S.S.; Mahari, W.A.W.; Cheng, C.K.; Omar, R.; Chong, C.T.; Chase, H.A. Recovery of diesel-like fuel from waste palm oil by pyrolysis using a microwave heated bed of activated carbon. Energy 2016, 115, 791-799. [CrossRef] 